\title{
Ambulatory Duchenne Muscular Dystrophy Children: Cross-sectional Correlation between Function, Quantitative Muscle Ultrasound and MRI
}

\author{
Hala Abdulhady MD', (D) Hossam M. Sakr MD² (D) Nermine S. Elsayed MD ${ }^{3}$, Tamer A. El-Sobky \\ $M D^{4}$, Nagia Fahmy $M D^{5}$, Amr M. Saadawy $M D^{2}$, Heba Elsedfy $M D^{3}$ \\ ${ }^{1}$ Department of Physical Medicine, Rheumatology and Rehabilitation, ${ }^{2}$ Department of Diagnostic and \\ Interventional Radiology and Molecular Imaging, ${ }^{3}$ Department of Medical Genetics, ${ }^{4}$ Division of \\ Pediatric Orthopedics, Department of Orthopedic Surgery, ${ }^{5}$ Neuromuscular Unit, Department of \\ Neuropsychiatry, Faculty of Medicine, Ain Shams University, Cairo, Egypt \\ "Corresponding author: drhossam_sakr@ med.asu.edu.eg
}

Acknowledgements: The authors thank Dr Khaled M. Abd Elaziz, Professor of Public Health, Ain Shams University for his help in performing the statistical analysis.

Ethical publication statement: We affirm that this report is consistent with the international ethical guidelines. Disclosures of conflicts of Interest: None of the authors has any conflict of interest to disclose Note: Part of the material in this work has been accepted as a poster presentation at Parent Project Muscular Dystrophy 20121 Annual Conference/ Virtual Meeting June 23- June 26 June 


\section{Ambulatory Duchenne Muscular Dystrophy Children: Cross-sectional Correlation between Function, Quantitative Muscle Ultrasound and MRI}

\section{Abstract}

Introduction/Aims: Duchenne muscular dystrophy (DMD) is a progressive genetic muscle disease. Quantitative muscle ultrasound (MUS), muscle MRI, and functional tools are important to delineate characteristics of muscle involvement. We aimed to establish correlations between clinical/functional and above-named imaging tools respecting their diagnostic and prognostic role in DMD children. Methods: A Prognostic cross-sectional retrospective study of 27 steroid-naive, ambulant male children/adolescents with genetically-confirmed DMD (mean age, $8.8 \pm 3.3$ years). Functional performance was assessed using motor function measure (MFM) which assess standing/transfer (D1), proximal (D2) and distal (D3) motor function. And sixminute-walk test (6MWT). Imaging evaluation included quantitative muscle MRI which measured muscle fat content in a specific location of right rectus femoris by mDixon sequence. Quantitative MUS measured muscle brightness in standardized US image as an indicator of muscle fat content. Results: We found a highly significant positive correlation between the mean MFM total score and 6MWT $(\mathrm{R}=0.537, \mathrm{P}=0.007)$. And a highly significant negative correlation between fat content by MUS and MFM total score $(\mathrm{R}=-0.603, \mathrm{P}=0.006)$ and its $\mathrm{D} 1$ subscore $(\mathrm{R}=-0.712, \mathrm{P}=0.001)$. And a significant negative correlation between fat content by US and 6MWT $(\mathrm{R}=-0.529, \mathrm{P}=0.02)$. And a significant positive correlation between muscle fat content by mDixon MRI and patient's age $(\mathrm{R}=0.617, \mathrm{P}=0.01)$. Discussion: Quantitative MUS correlates significantly with clinical/functional assessment tools as MFM and 6MWT, and augments their role in disease-tracking of DMD. Quantitative MUS has the potential to act as a substitute to functional assessment tools. The role for quantitative muscle MRI in disease-tracking should be further explored after elimination of confounding factors.

Keywords: Hereditary Muscular Diseases; Genetic Neuromuscular Diseases; Dystrophinopathies; Duchenne Muscular Dystrophies; Quantitative Magnetic Resonance Imaging; Muscle Ultrasonography; Motor Function Measure; 6Minute Walk Test; 
medRxiv preprint doi: https://doi.org/10.1101/2021.08.17.21262119; this version posted August 24, 2021. The copyright holder for this preprint

(which was not certified by peer review) is the author/funder, who has granted medRxiv a license to display the preprint in perpetuity.

It is made available under a CC-BY-NC-ND 4.0 International license .

\section{Introduction}

Duchenne muscular dystrophy (DMD) is a severe, progressive X-linked inherited disease that affects 1 in 36006000 live male births (Falzarano et al., 2015). DMD occurs as a result of mutations (mainly deletions) in the dystrophin gene (DMD; locus Xp21.2). The most common presenting feature is secondary deterioration of the motor milestones typically recognized at mid childhood. With time, untreated progressive muscle weakness, joint contractures, and cardio-pulmonary compromise affect quality of life. The disease eventually runs a fatal course by approximately 20 years of age (Suthar and Sankhyan, 2018; Falzarano et al., 2015). The management of DMD requires a multidisciplinary approach to improve the quality of life (Suthar and Sankhyan, 2018; Apkon et al., 2018; Salera et al., 2017).

Therapeutic interventions have recently demonstrated intense upswings in modifying the natural history of DMD. These interventions include; therapies that slow the decline in muscle strength and function as glucocorticoids and therapies that target the pathology of DMD or improve muscle growth and regeneration (Falzarano et al., 2015; Liew and Kang, 2013). Furthermore, gene therapies as gene-addition, exon-skipping, stop codon read through and genome-editing therapies aim at improving the expression and functionality of dystrophin protein. Other therapies work on a cellular level and aim at replacement of damaged muscle tissue. Both of the above therapies yielded encouraging preliminary results (Verhaart et al., 2019; Barthélémy et al., 2018). Nevertheless these therapeutic gains have accentuated the need for consistent, valid and reliable assessment tools/outcome measures to monitor responses to treatment and to act as prognostic indicators. Widely used clinical scales that measure the motor function and activities of ambulatory and non- ambulatory patients with DMD exist (Mcdonald et al., 2013; Mayhew et al., 2011; Bushby et al., 2010). Recently significant interest in the use of magnetic resonance imaging (MRI) of muscles as whole-body MRI, quantitative MRI and magnetic resonance spectroscopy (MRS) to monitor disease progression has evolved (Warman Chardon et al., 2019; Willcocks et al., 2017; Senesac et al., 2015). MRI is a valuable non-invasive tool to reveal distinct pathologic patterns of various hereditary muscular diseases (Aivazoglou et al., 2021) such as facioscapulohumeral muscular dystrophy (Leung, 2017; Fatehi et al., 2017; Gerevini et al., 2016; Leung et al., 2015; Díaz-Manera et al., 2015), sarcoglycanopathies (Tasca et al., 2018), congenital myopathies (Leung 2017; Klein et al., 2011), muscular dystrophies ( Sakr et al., 2021; Fu et al., 2016; Díaz-Manera et al., 2015), including DMD (Leung 2017; Polavarapu K et al., 2016; Li W et al., 2015). The use of quantitative muscle MRI and whole-body MRI has also been shown valuable to draw clinical-imaging-genetic 
medRxiv preprint doi: https://doi.org/10.1101/2021.08.17.21262119; this version posted August 24, 2021. The copyright holder for this preprint

(which was not certified by peer review) is the author/funder, who has granted medRxiv a license to display the preprint in perpetuity.

It is made available under a CC-BY-NC-ND 4.0 International license .

correlations and identify ideal sites for muscle biopsy (Warman Chardon et al., 2019; Sakr et al., 2021; Leung 2017; Fatehi et al., 2017; Polavarapu et al., 2016; Gerevini et al., 2016; Li et al., 2015). The combined use of quantitative muscle US and MRI showed promising results in regard to delineating disease stage and its relevance to functional status in facioscapulohumeral muscular dystrophy patients (Mul et al., 2018; Janssen et al., 2014). In DMD quantitative muscle MRI (Nagy et al., 2020; Bonati et al., 2015) and quantitative muscle ultrasound (US) (Zaidman et al., 2017) were found to be a satisfactory substitute to clinical/functional assessment tools as timed function tests in regard to monitoring disease progression.

Nevertheless, we are not aware of studies that investigated the clinical utility of quantitative muscle US and quantitative muscle MRI when used simultaneously with clinical functional tests in patients with DMD. The objectives of this study are: a) to assess the role of quantitative muscle US and muscle MRI as a potential diagnostic and prognostic tool in a series of ambulatory children with genetically-confirmed DMD, b) to draw relevant correlations between these two imaging modalities and clinical outcomes namely 6-minute walk test and motor function measure.

\section{Material and Methods}

This was a prognostic cross-sectional retrospective study. Twenty seven steroid-naive, ambulant male children/adolescents with genetically-confirmed DMD were enrolled. The mean age of patients was $8.8 \pm 3.3$ years (range, 3.1 to 18). The functional performance of patients was assessed using the motor function measure (MFM) (Vuillerot et al. 2010) and six-minute walk test (6MWT) (Mcdonald et al., 2013). MFM consists of 32 items (20 items for children $<7$ years). It assesses all three dimensions of motor performance including standing and transfer (D1) subscore, axial and proximal motor function (D2), and distal motor function (D3). The 6MWT a commonly used timed functional test that also sufficiently monitors changes in muscle function. The imaging evaluation included quantitative muscle MRI which measured muscle fat content in the right rectus femoris at the junction of the proximal $1 / 3 \&$ distal $2 / 3$ of thigh by mDixon sequence and quantitative muscle US which measured muscle brightness in standardized US image as an indicator of muscle fat content. Twenty five patients completed both functional tests, 21 patients completed the muscle US examination and 16 completed the muscle MRI examination. The study was approved by the Medical Ethics Research Committee of Faculty of Medicine, Ain Shams University, Egypt, number FMASU R 110 / 2021. Informed consent from participants or waived by the regulatory authority. 
medRxiv preprint doi: https://doi.org/10.1101/2021.08.17.21262119; this version posted August 24, 2021. The copyright holder for this preprint

(which was not certified by peer review) is the author/funder, who has granted medRxiv a license to display the preprint in perpetuity.

It is made available under a CC-BY-NC-ND 4.0 International license .

\section{Assessment tools}

The imaging and functional evaluation took place over two consecutive days where imaging evaluations were done prior to the functional tests. Patients who had sufficient cognitive ability to comply with verbal commands pertaining to the functional tests, were evaluated by the same examiner and approximately at the same time-point of the day. The functional tests were performed uniformly in the following order; MFM followed by 6MWT.

\section{Motor function measure (MFM)}

Items of the MFM-32 and MFM-20 are classified in 3 domains: D1: Standing and transfers (13 items for the MFM32 and 8 items for the MFM-20); D2: Axial and proximal motor function (12 items for the MFM-32 and 8 items for the MFM-20); D3: Distal motor function (7 items for the MFM-32 and 4 items for the MFM-20). Scores ranged from 0 to 3, as follows: (0) cannot perform the task, or cannot maintain the starting position, (1) initiated the task, (2) performs the movement incompletely, or completely but imperfectly (compensatory movements, position maintained for an insufficient duration of time, slowness, uncontrolled movement) and (3) performs the task fully and "normally" namely the movement is controlled, mastered, directed and performed at constant speed. The calculation of scores was expressed as a percentage in relation to the maximum score https://mfm-nmd.org/.

\section{Six-minute walk test}

The 6MWT was performed according to the ATS guidelines (ATS Committee, 2002), modified by having two examiners, one recording time and distances and one staying close to the patient for safety issues.

\section{Quantitative muscle MRI}

mDixon sequence was taken using Achieva 1.5-T MR machine (Philips Medical Systems, The Netherlands) with the following parameters; (Slice thickness $10 \mathrm{~mm}$, Spacing $5 \mathrm{~mm}$, Number of phase encoding steps: 268, Acquisition matrix 272/0/0/268, Flip angle 15), the images were transferred to workstation (ViewForum R 6.3). The mean fat and water signal of a region of interest (ROI) within the right rectus femoris muscle was measured at the junction between the proximal 1/3 and distal $2 / 3$ between its origin (from the anterior inferior iliac spine) and its insertion (at the upper pole of the patella) was measured.

\section{Quantitative muscle US}


medRxiv preprint doi: https://doi.org/10.1101/2021.08.17.21262119; this version posted August 24, 2021. The copyright holder for this preprint

(which was not certified by peer review) is the author/funder, who has granted medRxiv a license to display the preprint in perpetuity.

It is made available under a CC-BY-NC-ND 4.0 International license .

US in axial plane of the right rectus femoris muscle was taken at the junction between the proximal $1 / 3$ and distal $2 / 3$ between its origin (from the anterior inferior iliac spine) and its insertion (at the upper pole of the patella, using GE Logiq 7 machine (GE Healthcare, Waukesha, Wisconsin, USA) with high resolution linear probe 7-12 MHz . All the imaging parameters (including the probe frequency, depth, and gain) were constant, the images were transferred to a personal PC and mean grayscale (i.e. muscle echogenicity) was calculated using image histogram analysis software (ImageJ) and was used as an indication of muscle fat content.

\section{Statistical methods}

Data was revised for its completeness and consistency. Data entry was done on Microsoft Excel workbook. Quantitative data was summarized by mean, standard deviation while qualitative data was summarized by frequencies and percentages. The program used for data analysis was IBM SPSS statistics for windows version 23 (IBM Corp., Armonk, NY, USA). Chi-square test, student $\mathrm{t}$ test, and Pearson correlation coefficient were used in analysis of this study. Kappa test was done to measure level of agreement. A "P value" of less than 0.05 was considered statistically significant.

\section{Results}

Six patients $22 \%$ were $<7$ years of age. 19 patients $(70 \%)$ had exon deletions, $2(7 \%)$ had exon duplications, and 6 (22\%) had small mutations. Comparatively, patients with exon deletions had a lower mean MFM score without statistical significance. Tables 1 and 2 show the descriptive statistics of all clinical and imaging assessment tools used. We found a highly significant positive correlation between the 6MWT and the mean total MFM score $(\mathrm{R}=0.537, \mathrm{P}=0.007)$ and its $\mathrm{D} 1$ subscore $(\mathrm{R}=0.751, \mathrm{P}=0.000)$ (Figs. 1,2$)$. We found a highly significant negative correlation between fat content by muscle US and total MFM score $(\mathrm{R}=-0.603, \mathrm{P}=0.006)$ and its $\mathrm{D} 1$ subscore $(\mathrm{R}=-$ 0.712, $\mathrm{P}=0.001$ ) (Figs. 3, 4, 5). Additionally, we found a significant negative correlation between fat content by muscle US and 6MWT score ( $\mathrm{R}=-0.529, \mathrm{P}=0.02)$ (Table 3). This denotes that the higher the fat replacement in muscles of the thigh, the lower the scores of MFM and its D1 subscore and the lower meters achieved by patients in 6MWT. We found a significant positive correlation between patient's age and muscle fat content by mDixon MRI $(\mathrm{R}=0.617, \mathrm{P}=0.01)$. However, we did not find a statistically significant correlation between both muscle fat content and muscle water content by mDixon MRI and neither total MFM score nor 6MWT (Table 4) (Figs. 6, 7) (Fig. S8). Statistical correlations between age and both mean total MFM scores and subscores, and 6MWT scores were nonsignificant. For additional information see (File S1). 
medRxiv preprint doi: https://doi.org/10.1101/2021.08.17.21262119; this version posted August 24, 2021. The copyright holder for this preprint

(which was not certified by peer review) is the author/funder, who has granted medRxiv a license to display the preprint in perpetuity.

It is made available under a CC-BY-NC-ND 4.0 International license .

\section{Discussion}

Corticosteroids remain the mainstay of treatment in DMD children whereas gene therapeutic modalities are emerging (Rivera et al., 2020; Frank et al., 2020) among others (Nagy et al., 2019). Both treatment modalities aim at improving the child's functional status. Recent advances in therapeutics for the treatment of DMD children have sparked significant interest in finding reliable clinical and imaging assessment tools to monitor responsiveness to these treatment modalities. The current study has incorporated various clinical and imaging assessment tools to explore their diagnostic and prognostic role in genetically-confirmed ambulatory and steroid-naïve DMD children and adolescents. Whereas quantitative US depends on measuring muscle echogenicity using the mean gray scale of a ROI within a selected muscle (Zaidman et al., 2017), quantitative MRI depends on measuring muscle fat replacement (Bonati et al., 2015; Burakiewicz et al., 2017). Both quantitative imaging tools have proved to aid clinical assessment fundamentally.

Our study implications are twofold. Firstly, it confirmed the widely acknowledged role of MFM and 6MWT as reliable and clinically meaningful assessment tools in DMD children (Nagy et al., 2020; Vuillerot et al., 2010; Mcdonald et al., 2013). Secondly, our study introduced a statistically significant positive correlations between scores of these clinical assessments tools namely MFM and 6MWT on the one hand and quantitative muscle US in DMD children. This highlights the potential clinical utility of quantitative muscle US for DMD monitoring. And underscores the role of quantitative muscle US as an important substitute and supplement to clinical functional assessment tools. This role has been elucidated in both cross-sectional (Shklyar et al., 2015) and longitudinal (Zaidman et al., 2017) study designs capable of monitoring disease progression in DMD children. Contrastingly, quantitative muscle fat content measured by US did not show a statistically significant correlation with patient's age.

Quantitative muscle MRI -as per T2 mapping and mDixon- has been found helpful for delineating upper (Forbes et al., 2020; Willcocks et al., 2017) and lower extremity (Naarding et al., 2020; Yin et al., 2019; Bonati et al., 2015) muscle involvement and to be a satisfactory predictor of both strength of the investigated muscles or of the overall function of the investigated extremity in DMD children. However, our results did not establish a similarly significant correlation between the scores of these clinical assessments tools namely MFM and 6MWT and quantitative muscle MRI namely muscle fat content and muscle water content by mDixon MRI. This may be attributed to the limitations of our study. Our study contained multiple clinical and imaging assessment tools 
medRxiv preprint doi: https://doi.org/10.1101/2021.08.17.21262119; this version posted August 24, 2021. The copyright holder for this preprint (which was not certified by peer review) is the author/funder, who has granted medRxiv a license to display the preprint in perpetuity. It is made available under a CC-BY-NC-ND 4.0 International license .

(dependent variables). Additionally, its retrospective and cross-sectional nature does not allow for complete bias control in terms of standardization of patient characteristics among others. Moreover, longitudinal study designs have a greater potential to consolidate evidence for the use of both quantitative muscle US and muscle MRI as a substitute or a supplement to functional assessment tools in disease tracking and monitoring response to treatment of DMD patients. Further, the diversity of clinical assessment tools in general and functional tools in specific used across studies needs to be considered when interpreting the imaging-clinical correlation results (Senesac et al., 2019). Interestingly, quantitative muscle fat content measured by mDixon MRI showed a statistically positive correlation with patient's age. This is a clinically meaningful correlation. And it supports the assumption that the above-noted non-significant correlations between the clinical MFM and 6MWT scores, and quantitative fat content by mDixon MRI is mainly due study limitaions. Additionally, of note is that statistical significance does not necessary equate to clinical significance. Consequently all findings should be interpreted cautiously and within clinical context.

\section{Conclusions}

Quantitative muscle US correlates significantly with clinical/functional assessment tools as MFM and 6MWT, and augments their promising role in disease tracking of DMD children. In that regard quantitative muscle US has the potential to act as substitute or supplement to functional assessment tools. The potential role for all components of quantitative muscle MRI in disease tracking should be further explored after elimination of confounding factors. The presence of multiple clinical and imaging assessment tools (dependent variables) and study design-related limitations may have underpowered our statistical correlations.

\section{Supplementary Information}

Figure S8: Transverse US image of the right thigh of three different children with DMD

File S1: Tables S5 to S25

\section{References}

Aivazoglou LU, Guimarães JB, Link TM, et al. MR imaging of inherited myopathies: a review and proposal of imaging algorithms. Eur Radiol 2021. https://doi.org/10.1007/s00330-021-07931-9

Apkon SD, Alman B, Birnkrant DJ, et al. Orthopedic and surgical management of the patient with Duchenne muscular dystrophy. Pediatrics 2018;142(Suppl 2):S82-S89. https://doi.org/10.1542/peds.2018-0333J 
medRxiv preprint doi: https://doi.org/10.1101/2021.08.17.21262119; this version posted August 24, 2021. The copyright holder for this preprint

(which was not certified by peer review) is the author/funder, who has granted medRxiv a license to display the preprint in perpetuity.

It is made available under a CC-BY-NC-ND 4.0 International license .

ATS Committee on Proficiency Standards for Clinical Pulmonary Function Laboratories. ATS statement: guidelines for the six-minute walk test. Am J Respir Crit Care Med 2002;166(1):111-7. https://doi.org/10.1164/ajrccm.166.1.at1102

Barthélémy F, Wein N. Personalized gene and cell therapy for Duchenne Muscular Dystrophy. Neuromuscul Disord 2018;28:803-24. https://doi.org/10.1016/j.nmd.2018.06.009

Bonati U, Hafner P, Schädelin S, et al. Quantitative muscle MRI: A powerful surrogate outcome measure in Duchenne muscular dystrophy. Neuromuscul Disord 2015;25:679-85. https://doi.org/10.1016/j.nmd.2015.05.006

Burakiewicz J, Sinclair CDJ, Fischer D, et al. Quantifying fat replacement of muscle by quantitative MRI in muscular dystrophy. J Neurol 2017;264:2053-2067. https://doi.org/10.1007/s00415-017-8547-3

Bushby K, Finkel R, Birnkrant D, et al. Diagnosis and management of Duchenne muscular dystrophy, part 1: diagnosis, and pharmacological and psychosocial management. Lancet Neurol 2010;9:77-93. https://doi.org/10.1016/S14744422(09)70271-6

Falzarano MS, Scotton C, Passarelli C, Ferlini A. Duchenne Muscular Dystrophy: From Diagnosis to Therapy. Molecules 2015;20:18168-84. https://doi.org/10.3390/molecules201018168

Forbes SC, Arora H, Willcocks RJ, et al. Upper and lower extremities in Duchenne muscular dystrophy evaluated with quantitative MRI and Proton MR spectroscopy in a multicenter cohort. Radiology 2020;295:616-625. https://doi.org/10.1148/radiol.2020192210

Frank DE, Schnell FJ, Akana C, et al. Increased dystrophin production with golodirsen in patients with Duchenne muscular dystrophy. Neurology 2020;94:e2270-e2282. https://doi.org/10.1212/WNL.0000000000009233

Janssen BH, Pillen S, Voet NB, Heerschap A, van Engelen BG, van Alfen N. Quantitative muscle ultrasound versus quantitative magnetic resonance imaging in facioscapulohumeral dystrophy. Muscle Nerve 2014;50:968-75. https://doi.org/10.1002/mus.24247

Leung DG. Magnetic resonance imaging patterns of muscle involvement in genetic muscle diseases: a systematic review. J Neurol 2017;264:1320-33. https://doi.org/10.1007/s00415-016-8350-6

Liew WKM, Kang PB. Recent developments in the treatment of Duchenne muscular dystrophy and spinal muscular atrophy. Ther Adv Neurol Disord 2013;6:147-60. https://doi.org/10.1177/1756285612472386

Mayhew A, Cano S, Scott E, et al. Moving towards meaningful measurement: Rasch analysis of the North Star Ambulatory Assessment in Duchenne muscular dystrophy. Dev Med Child Neurol 2011;53:535-42. https://doi.org/10.1111/j.14698749.2011.03939.x 
medRxiv preprint doi: https://doi.org/10.1101/2021.08.17.21262119; this version posted August 24, 2021. The copyright holder for this preprint

(which was not certified by peer review) is the author/funder, who has granted medRxiv a license to display the preprint in perpetuity.

It is made available under a CC-BY-NC-ND 4.0 International license .

Mcdonald CM, Henricson EK, Abresch RT, et al. The 6-minute walk test and other endpoints in Duchenne muscular dystrophy: longitudinal natural history observations over 48 weeks from a multicenter study. Muscle Nerve 2013;48:343-56. https://doi.org/10.1002/mus.23902

Mul K, Horlings CGC, Vincenten SCC, Voermans NC, van Engelen BGM, van Alfen N. Quantitative muscle MRI and ultrasound for facioscapulohumeral muscular dystrophy: complementary imaging biomarkers. J Neurol 2018;265:2646-55. https://doi.org/10.1007/s00415-018-9037-y

Naarding KJ, Reyngoudt H, van Zwet EW, et al. MRI vastus lateralis fat fraction predicts loss of ambulation in Duchenne muscular dystrophy. Neurology 2020;94:e1386-e1394. https://doi.org/10.1212/WNL.0000000000008939

Nagy S, Hafner P, Schmidt S, et al. Tamoxifen in Duchenne muscular dystrophy (TAMDMD): study protocol for a multicenter, randomized, placebo-controlled, double-blind phase 3 trial. Trials 2019;20:637. https://doi.org/10.1186/s13063-019-3740-6

Nagy S, Schädelin S, Hafner P, et al. Longitudinal reliability of outcome measures in patients with Duchenne muscular dystrophy. Muscle Nerve 2020;61:63-68. https://doi.org/10.1002/mus.26690

Polavarapu K, Manjunath M, Preethish-Kumar V, et al. Muscle MRI in Duchenne muscular dystrophy: Evidence of a distinctive pattern. Neuromuscul Disord 2016;26:768-74. https://doi.org/10.1016/j.nmd.2016.09.002

Rivera SR, Jhamb SK, Abdel-Hamid HZ, et al. Medical management of muscle weakness in Duchenne muscular dystrophy. PLoS One 2020;15:e240687. https://doi.org/10.1371/journal.pone.0240687

Sakr HM, Fahmy N, Elsayed NS, et al. Whole-Body muscle MRI characteristics of LAMA2-related congenital muscular dystrophy children: An emerging pattern. Neuromuscul Disord 2021. DOI: https://doi.org/10.1016/j.nmd.2021.06.012

Salera S, Menni F, Moggio M, Guez S, Sciacco M, Esposito S. Nutritional challenges in Duchenne muscular dystrophy. Nutrients. 2017;9:594. https://doi.org/10.3390/nu9060594

Senesac CR, Lott DJ, Forbes SC, et al. Longitudinal evaluation of muscle composition using magnetic resonance in 4 boys with Duchenne muscular dystrophy: Case series. Phys Ther 2015;95:978-88. https://doi.org/10.2522/ptj.20140234

Senesac CR, Lott DJ, Willcocks RJ, et al. Lower extremity functional outcome measures in Duchenne muscular dystrophy-A delphi survey. J Neuromuscul Dis 2019;6:75-83. doi: 10.3233/JND-180337

Shklyar I, Geisbush TR, Mijialovic AS, et al. Quantitative muscle ultrasound in Duchenne muscular dystrophy: a comparison of techniques. Muscle Nerve 2015;51:207-13. https://doi.org/10.1002/mus.24296

Suthar R, Sankhyan N. Duchenne Muscular Dystrophy: A Practice Update. Indian J Pediatr 2018;85:276-281. https://doi.org/10.1007/s12098-017-2397-y 
medRxiv preprint doi: https://doi.org/10.1101/2021.08.17.21262119; this version posted August 24, 2021. The copyright holder for this preprint (which was not certified by peer review) is the author/funder, who has granted medRxiv a license to display the preprint in perpetuity.

It is made available under a CC-BY-NC-ND 4.0 International license .

Tasca G, Monforte M, Díaz-Manera J, et al. MRI in sarcoglycanopathies: a large international cohort study. J Neurol Neurosurg Psychiatry 2018;89:72-7. http://dx.doi.org/10.1136/jnnp-2017-316736

Verhaart IEC, Aartsma-Rus A. Therapeutic developments for Duchenne muscular dystrophy. Nat Rev Neurol 2019;15:373-86. https://doi.org/10.1038/s41582-019-0203-3

Vuillerot C, Girardot F, Payan C, Fermanian J, Iwaz J, De Lattre C, et al. Monitoring changes and predicting loss of ambulation in Duchenne muscular dystrophy with the Motor Function Measure. Dev Med Child Neurol 2010;52:60-5. https://doi.org/10.1111/j.1469-8749.2009.03316.x

Warman Chardon J, Díaz-Manera J, Tasca G, et al. MYO-MRI diagnostic protocols in genetic myopathies. Neuromuscul Disord 2019;29:827-41. https://doi.org/10.1016/j.nmd.2019.08.011

Willcocks RJ, Triplett WT, Forbes SC, et al. Magnetic resonance imaging of the proximal upper extremity musculature in boys with Duchenne muscular dystrophy. J Neurol 2017;264:64-71. https://doi.org/10.1007/s00415-016-8311-0

Zaidman CM, Wu JS, Kapur K, et al. Quantitative muscle ultrasound detects disease progression in Duchenne muscular dystrophy. Ann Neurol 2017;81:633-640. https://doi.org/10.1002/ana.24904

Yin L, Xie ZY, Xu HY, et al. T2 mapping and fat quantification of thigh muscles in children with Duchenne muscular dystrophy. Curr Med Sci 2019;39:138-145. https://doi.org/10.1007/s11596-019-2012-8

\section{Tables}

Table 1. Descriptive statistics of functional assessment tools.

\begin{tabular}{llllllll}
\hline & $\mathrm{N}$ & Mean & SD & IQR & Median & Min & Max \\
\hline Age & 27 & 8.7 & 3.4 & $6.6-10.2$ & 8.6 & 3.1 & 18 \\
\hline MFM & & & & & & & 96.3 \\
\hline Total\% & 25 & 74.3 & 17.6 & $63.9-88.0$ & 61.5 & 0 & 97.4 \\
\hline D1\% & 25 & 57.7 & 26.8 & $37.1-76.9$ & 94.4 & 30.5 & 100 \\
\hline D2\% & 25 & 86.2 & 17.3 & $83.3-97.2$ & 85.7 & 42.8 & 100 \\
\hline D3\% & 25 & 84.8 & 13.5 & $75.5-95.2$ & 304.0 & 525 \\
\hline $\begin{array}{l}\text { 6MWT } \\
\text { (meters) }\end{array}$ & 25 & 291.4 & 112.4 & $241.5-370$ & & & \\
\hline
\end{tabular}

N: Number of patients, MFM: motor function measure, 6MWT: 6-minute walk test, SD: Standard Deviation, IQR: Interquartile range, Min: Minimum, Max: Maximum

Table 2. Descriptive statistics of imaging assessment tools.

\begin{tabular}{llllllll}
\hline & $\mathrm{N}$ & Mean & SD & IQR & Median & Min & Max \\
\hline US & 21 & 83.5 & 29.1 & $57.0-108.6$ & 84.2 & 43.6 & 141.4 \\
\hline mDixon fat & 16 & 77.9 & 60.7 & $44.1-86.5$ & 61.6 & 30.2 & 272 \\
\hline mDixon water & 16 & 375.1 & 145.7 & $321.2-468.7$ & 431.3 & 52.1 & 535.7 \\
\hline
\end{tabular}

N: Number of patients, SD: Standard Deviation, IQR: Interquartile range, Min: Minimum, Max: Maximum 
Table 3. Correlation coefficient between age, functional assessment tools namely MFM and 6MWT and muscle fat content by ultrasound.

\begin{tabular}{l|l}
\hline & US fat content \\
\hline MFM total score & $\mathbf{R}=\mathbf{0 . 6 0 3}$ \\
& $\mathbf{P = 0 . 0 0 6 * *}$ \\
\hline D1 subscore & $\mathbf{R}=\mathbf{- 0 . 7 1 2}$ \\
& $\mathbf{P}=\mathbf{0 . 0 0 1} * *$ \\
\hline D2 subscore & $\mathrm{R}=-0.127$ \\
& $\mathrm{P}=0.6$ \\
\hline D3 subscore & $\mathrm{R}=0.101$ \\
& $\mathrm{P}=0.6$ \\
\hline Age & $\mathrm{R}=0.237$ \\
\hline 6MWT & $\mathrm{P}=0.3$ \\
\hline
\end{tabular}

MFM: motor function measure, 6MWT: 6-minute walk test.

Table 4. Correlation coefficient between age, functional assessment tools namely MFM and 6MWT and muscle fat and water content by mDixon MRI.

\begin{tabular}{l|l|l}
\hline N=16 & mDixon Fat & mDixon water \\
\hline Age & $\mathbf{R}=\mathbf{0 . 6 1 7}$ & $\mathrm{R}=-0.208$ \\
& $\mathbf{P}=\mathbf{0 . 0 1} *$ & $\mathrm{P}=0.4$ \\
\hline MFM total score & $\mathrm{R}=-0.140$ & $\mathrm{R}=-0.005$ \\
& $\mathrm{P}=0.6$ & $\mathrm{P}=0.9$ \\
\hline D1 sub score & $\mathrm{R}=-0.235$ & $\mathrm{R}=0.056$ \\
& $\mathrm{P}=0.3$ & $\mathrm{P}=0.8$ \\
\hline D2 sub score & $\mathrm{R}=0.164$ & $\mathrm{R}=-0.239$ \\
& $\mathrm{P}=0.5$ & $\mathrm{P}=0.4$ \\
\hline D3 sub score & $\mathrm{R}=0.152$ & $\mathrm{R}=-0.228$ \\
& $\mathrm{P}=0.5$ & $\mathrm{P}=0.4$ \\
\hline 6MWT & $\mathrm{R}=-0.208$ & $\mathrm{R}=0.224$ \\
& $\mathrm{P}=0.4$ & $\mathrm{P}=0.4$ \\
\hline
\end{tabular}

*: Statistically significant. MFM: motor function measure, 6MWT: 6-minute walk test. 


\section{Figures}

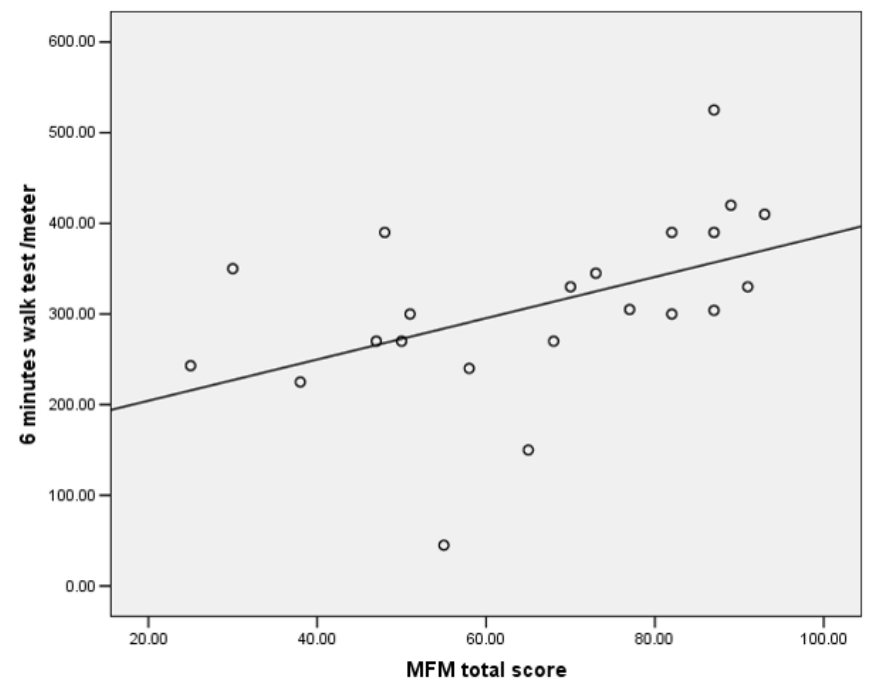

Figure 1: Correlation coefficient between Motor Function Measure (MFM) total score and 6-minute walk test showed a $-\mathrm{P}<0.01-$ a highly significant positive correlation.

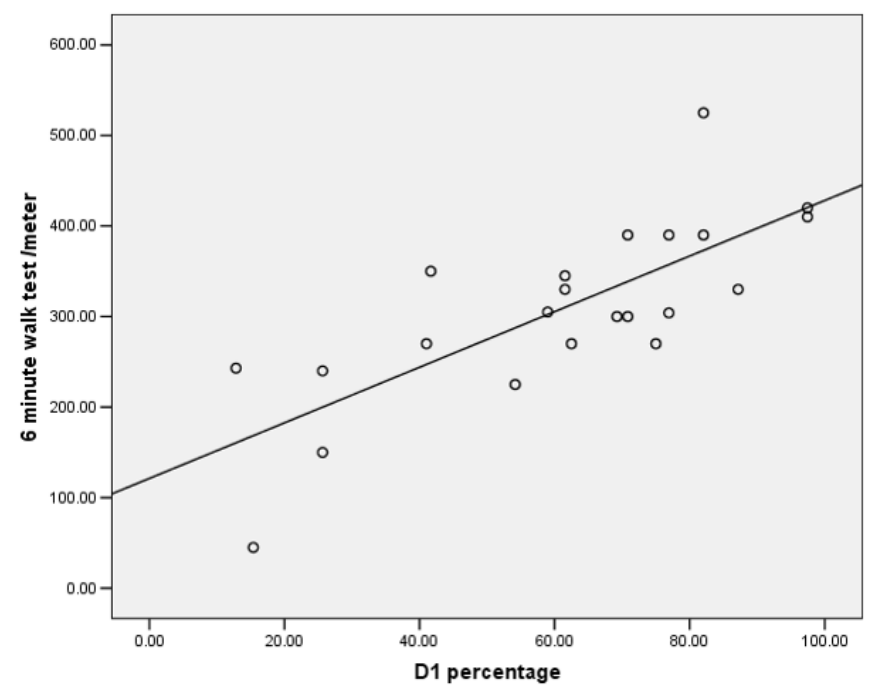

Figure 2: Correlation coefficient between motor function measure (MFM) D1 subscore percentage and 6-minute walk test showed $-\mathrm{P}<0.01$ - a highly significant positive correlation. 


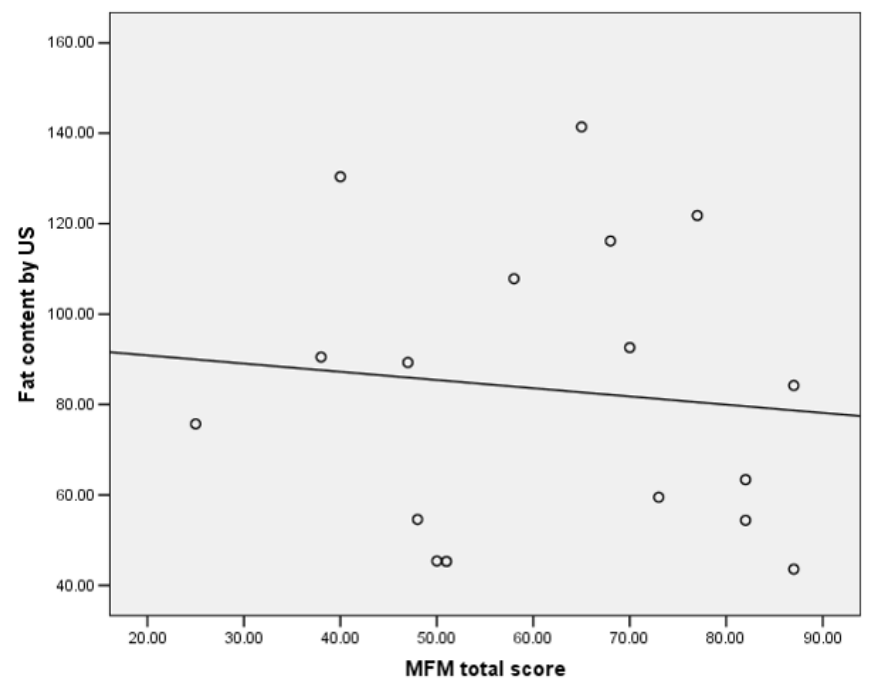

Figure 3: Correlation coefficient between motor function measure (MFM) total score and fat content by muscle ultrasound examination Showed a $-\mathrm{P}<0.05$ - a significant negative correlation.

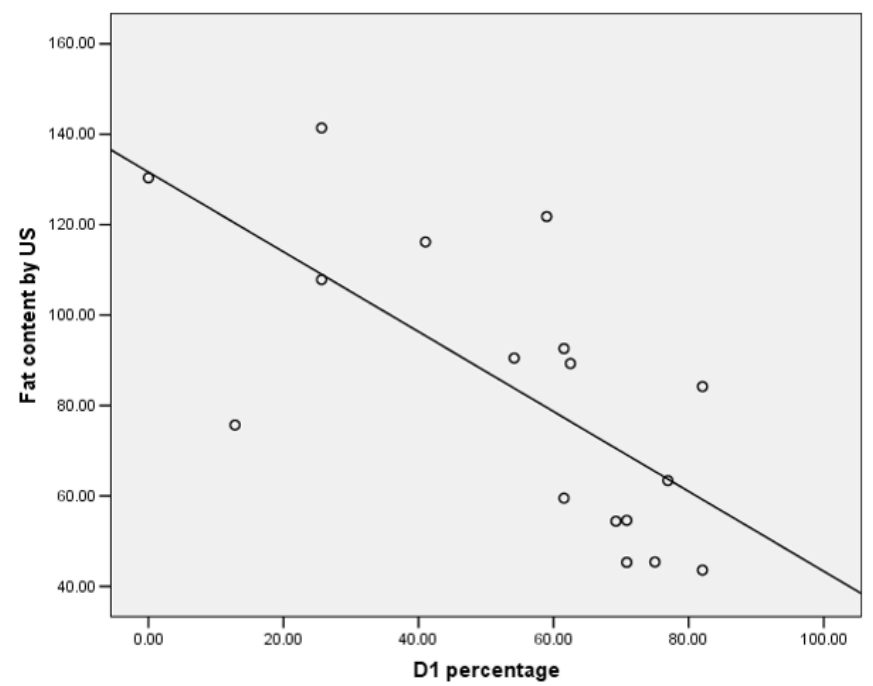

Figure 4: Correlation coefficient between motor function measure (MFM) D1 subscore percentage and fat content by muscle ultrasound examination $-\mathrm{P}<0.01$ - a highly significant negative correlation. 


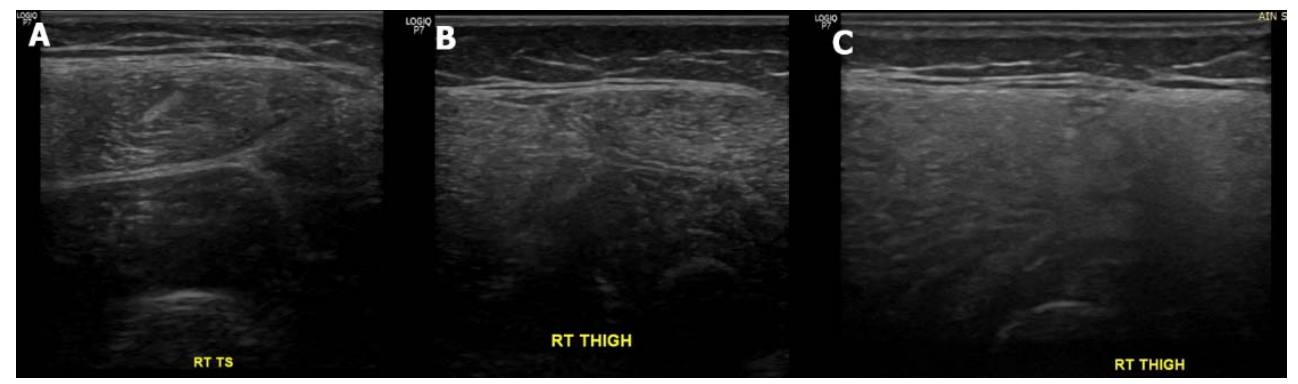

Figure 5. (A-C): Transverse US image of the right thigh of three different patients (A, B \& C) showing different degrees of fatty infiltration of the quadriceps muscle as per increased echogenicity and blurred cortical surface of the femur. The mean histogram is $53,76 \& 80$ respectively.

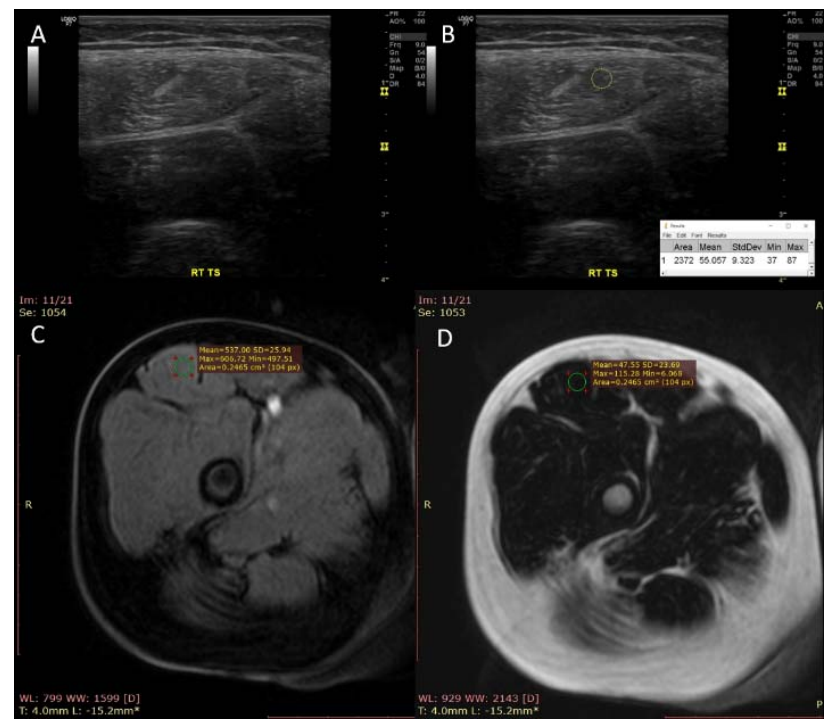

Figure 6. (A-D): A patient with Duchenne muscular dystrophy. (A) Transverse US image of the right thigh taken at the junction between the proximal $1 / 3$ and distal $2 / 3$ between its origin (from the anterior inferior iliac spine) and its insertion (at the upper pole of the patella) showing fatty infiltration of the quadriceps muscle as shown by increased echogenicity and blurred cortical surface of the femur. (B) The same image in (A) analyzed by ImageJ software with the ROI is within the rectus femoris muscle, mean histogram, 55. (C, D) Axial MRI image (mDixon sequence) with the region of interest (ROI) within the right rectus femoris muscle at the junction between the proximal $1 / 3$ and distal $2 / 3$ between its origin (from the anterior inferior iliac spine) and its insertion (at the upper pole of the patella), mean fat \& water signals were $66 \& 546$ respectively. 


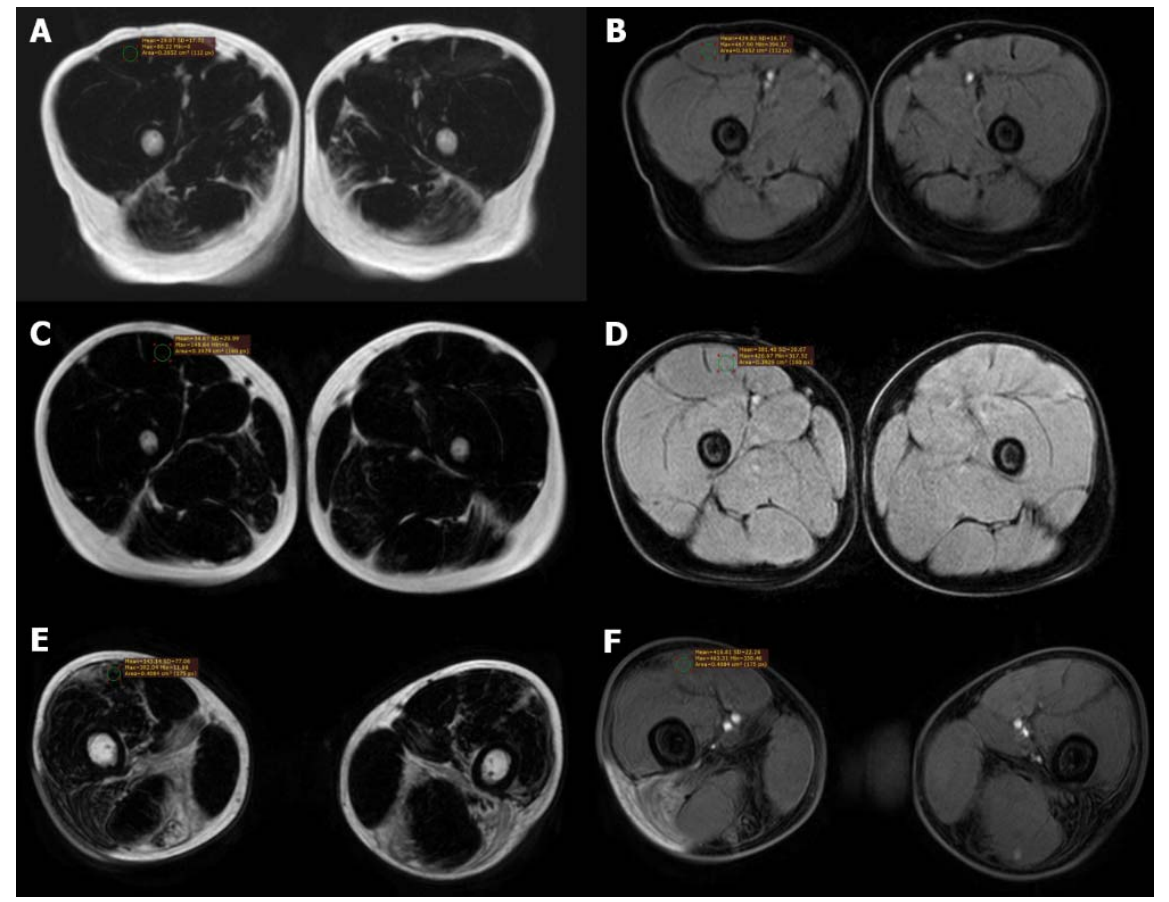

Figure 7. (A-F): Axial MRI image (mDixon sequence) in three different patients with DMD showing fat (A, C \& E) and water (B, D \& F) signal. The mean fat signals were $29,35 \& 143$ respectively while those of water were $430,351 \& 416$ respectively.

\section{Quantitative Clinical-Imaging Correlations in Ambulatory DMD}

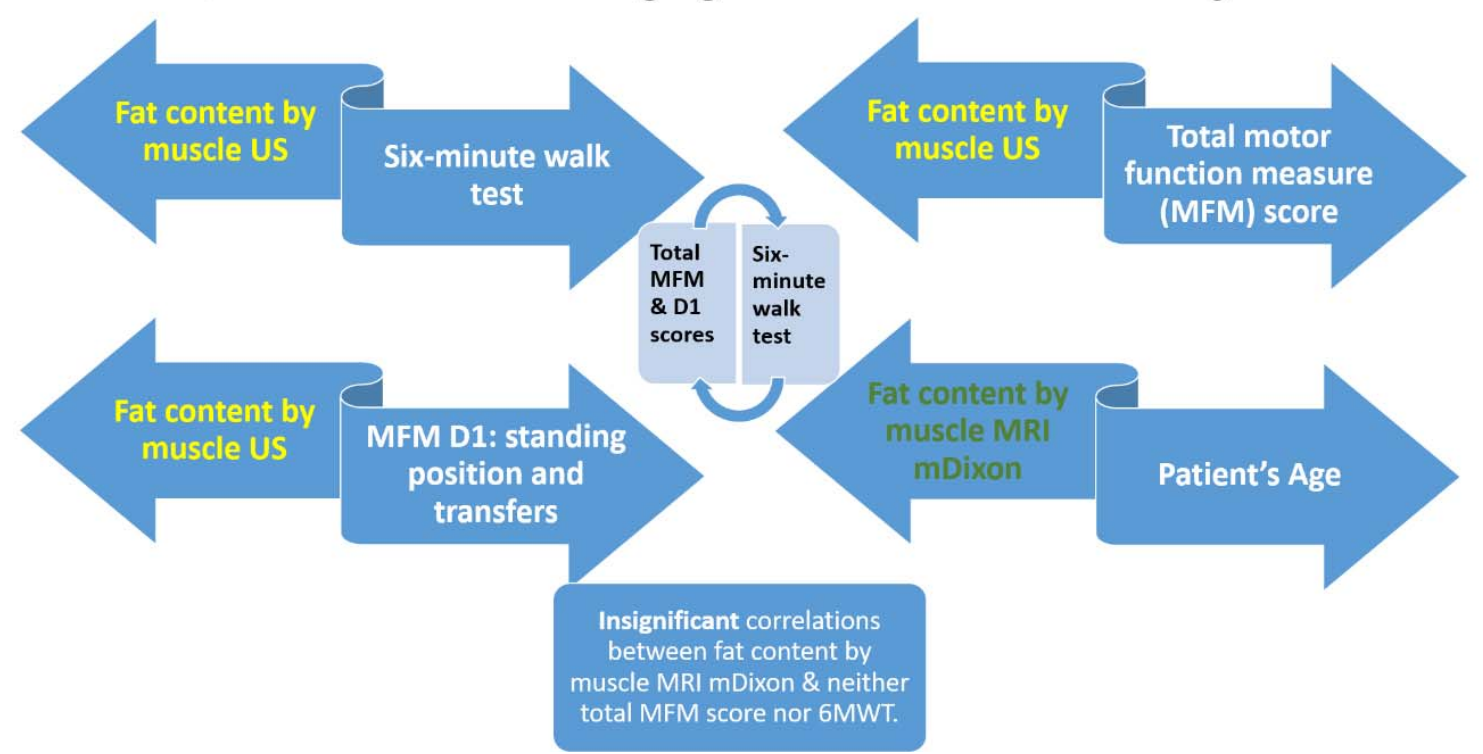

Graphical abstract: Divergent arrows represent negative correlations, while convergent the arrow represents a positive correlation. 
medRxiv preprint doi: https://doi.org/10.1101/2021.08.17.21262119; this version posted August 24, 2021. The copyright holder for this preprint (which was not certified by peer review) is the author/funder, who has granted medRxiv a license to display the preprint in perpetuity.

It is made available under a CC-BY-NC-ND 4.0 International license. 